\title{
Research of the Construction of Bilingual Teaching Staffs in Chinese Colleges and Universities
}

\author{
Xiuling Liu \\ School of Foreign Studies, Xi'an University of Arts and Science, Xi'an, Shaanxi, China, 710065
}

Keywords: Bilingual teaching; Teaching staffs; Approach

\begin{abstract}
At present, the global development trend of higher education in all countries is the development trend of international higher education, and the competition among countries is mainly reflected in the competition of high-level compound talents and comprehensive national strength. In order to adapt to the current international situation and meet the domestic demand for high-end talents, China's education sector attaches great importance to the development of bilingual teaching at colleges and universities. However, the serious shortage of qualified teachers has become the bottleneck restricting the development of bilingual teaching at higher educational institutions in China. In view of this situation, this paper defines the concept of "bilingual teaching" and proposes what qualities a qualified bilingual teacher should have according to the current development of bilingual teaching at China's higher educational institutions, and discusses methods to solve the shortage of bilingual teaching staffs at Chinese colleges and universities.
\end{abstract}

\section{Introduction}

The 21 st century is a new century of rapid development of high technology and global economic integration, in which the competition between countries is mainly concentrated in the competition in talents and comprehensive national strength. Therefore, the development of higher education in various countries is developing towards the internationalization of higher education. At present, China's national economy grows rapidly, so is the influence of its economy, science and technology and culture in the world. After China joins the WTO, it has become an urgent issue as how to integrate with international education and cultivate high-level compound talents suitable for internationalization so as to promote the all-round, coordinated and sustainable development of China's economy, science and technology, culture and society. Therefore, the National Ministry of Education clarifies in the No.4 document "Several Opinions on Enhancing Undergraduate Teaching at Colleges and Universities and Improving Teaching Quality" in 2001 that colleges and universities should actively carry out bilingual teaching, and then at the end of 2004, it issued the "Several Opinions about Further Promoting Bilingual Teaching for Undergraduate Education" and clarified that "to carry out bilingual teaching is the demand of accelerating the internationalization process of China's higher education and also the urgent demand to cultivate high-quality talents with international competitiveness and improve China's comprehensive national strength." This document requires the education administrative departments of each province, autonomous region and municipality directly under the central government and university to have a full understanding of it and promote bilingual teaching as a major measure to further deepening reform of education according to the requirement that "education should be oriented to modernization, the world and future". Facing the current international and domestic situation and actively responding to the spirit of the Ministry of Education, bilingual education in colleges and universities to further strengthen the bilingual education has become the focus of the current teaching reform. However, the scarcity of qualified bilingual teachers has become the bottleneck restricting the development of bilingual education in China's higher education. 


\section{Current Status of Carrying out Bilingual Teaching at Colleges and Universities in China and the Scarcity of Teachers}

In terms of the practice of carrying out bilingual teaching at Chinese colleges and universities, according to incomplete statistics, at present, nearly one hundred colleges and universities have carried out bilingual teaching practices, and some important colleges and universities have obtained great progress and good effects in bilingual teaching. For example, 54 courses in Tsinghua University are taught in English (including homework and exams), and more than 500 core courses take excellent textbooks of well-known foreign colleges and universities as the reference books. In addition, more than 30 courses in Beijing University and 8 courses in Sun Yat-sen University adopt original foreign textbooks, Fudan University introduces more than 7600 textbooks from Harvard University, and Huazhong University of Science and Technology and Wuhan University take the initiative to carry out pilot work of bilingual teaching and achieve good effects.

Meanwhile, some non-key colleges and universities also introduce bilingual teaching to varying degrees and obtain some substantial progress. However, the effect of carrying out bilingual teaching at most colleges and universities, especially some non-key colleges and universities is not so ideal. They either stay at the stage that teachers help students read English textbooks and make bilingual courses become language courses or just stay on the form that teachers just introduce several English professional terms at class or print some relevant articles of English literatures to make students read them on their own. However, the teaching plans, textbooks, homework and exams are all in Chinese, so it fails to achieve the purpose of helping students to improve their English application abilities, and many students feel that they neither improve their English ability nor have a good mastery of professional knowledge.

The most important factor to carry out bilingual teaching practice is to have qualified bilingual teachers. But at present, most of the bilingual teaching teachers in our universities are very scarce. The current our country higher education bilingual teaching practice, the overall effect is not satisfactory, uneven in quality, situation. Some key institutions such as Tsinghua University, Peking University and other bilingual teaching practice work at schools because they have a considerable number of qualified and even excellent bilingual teachers. Since bilingual teaching in China is still in its infancy, there is no formal training institution for bilingual education and bilingual teachers. Therefore, most of the colleges take measures either to directly transfer to English teachers on the bilingual teaching of professional teachers, either in English based on the bilingual teaching and strong interest in the selection of outstanding teachers training. Although these measures are temporary relief but it is not a permanent solution as pressing danger. Although English teachers have a good command of English teaching skills, but the professional curriculum familiarity, depth obviously cannot be compared with professional teachers. The result is likely to be bilingual courses into another language courses, students may understand English, but it is difficult to learn well and deep professional knowledge. But the English foundation is good, the interested specialized teacher passes through the simple training to embark on the bilingual teaching platform quickly, although they have the high education degree, has certain English reading, the translation ability. But it is difficult to meet the requirements of bilingual teaching in pronunciation and oral expression. Therefore, bilingual courses tend to be rigid bilingual courses, teachers often only help students will read English textbooks, without the use of English communication between teachers and students, not to mention English thinking and solving problems.

\section{Qualities a Qualified Bilingual Teacher Should Have}

Bilingual Teachers Should Be Excellent Highly Educated Teachers. Bilingual teachers should use English textbooks, English lessons, lesson plans, writing assignments, students and teachers of English exam, so I want to listen to, say, read, write, translate and communicate the degree. The long-term practice shows that foreign bilingual education, bilingual teacher education, language ability, teaching ability, teaching strategies, teaching beliefs, values, attitudes are deeply affect the 
success and failure of students. That is to say, the higher the comprehensive quality of bilingual teachers is,

the higher the comprehensive quality of bilingual teachers is, the higher their teachers' moral cultivation will be. Therefore, bilingual teachers in Colleges and universities should have high education and excellent professional teachers. Because highly educated can make them have a solid professional basic knowledge, extensive cultural training and rich educational theory; At the same time, good professional ethics can also make them respect hillock love industry, with positive teaching attitude care for students, due to the next responsible. They have the correct educational values, can continue to learn advanced educational concepts at home and abroad, and constantly enrich and improve their teaching content and means; Their deep professional qualities make them naturally have outstanding teaching ability, organizational ability and scientific research ability, their teaching effect will be more prominent.

Bilingual Teachers Should Also Have Strong English Practical Ability. The most direct and main starting point of bilingual teaching in China is to improve students' English application level. So as to cultivate high-quality talents with international standards, which is related to China's comprehensive national strength and international competitiveness; This is not only the need for the realization of the strategic goal of "leaping development of social productive forces", but also the practical need of regional development and the future development of students. Therefore, bilingual teachers in bilingual teaching in Colleges and universities in China must master English as a tool. We should have English pure, accurate pronunciation, voice loud, so as to ensure that the students in the teaching and effective communication and good teaching effect. Secondly, bilingual teachers should use authentic English sentences to convey professional knowledge in the course of lectures, so as to ensure the correct and steady improvement of students' English application level. Bilingual teachers should use English textbooks, English lessons, lesson plans, writing assignments, students and teachers of English exam, so I want to listen to, say, read, write, translate and communicate the degree.

Bilingual Teachers Should Be Bilingual and Dual Cultural. Bilingual teaching is carried out in two languages. In China, mainly in Chinese and English, mainly for the use of English to carry out bilingual teaching. The change of teaching language is not only the change of language, but also the conflict and fusion of culture behind the language. Bilingual teaching can reflect different cultures, ways of thinking and values. Therefore, bilingual teaching should not only cultivate double voice, but also cultivate dual culture. Based on this, the two- language level of qualified bilingual teachers in China should not only have high, but also have to respect the dual culture attitude, to be familiar with the two kinds of languages and the cultural background, understand the cultural differences of two or more languages, with respect to two or more languages of traditional culture. UNESCO and other international education institutions have explicitly put forward the importance of cross-cultural education and international understanding education in twenty-first Century. "Contribution" education for the cultural development of the international documents that intercultural education or multicultural education "to promote respect for diversity, mutual understanding and rich", "promoting international understanding, and with all kinds of possible rejection struggle", "the aim should be to understand oneself from the culture of the people to appreciate other people's culture, and finally the appreciation of world culture." With the increasing degree of interdependence among countries all over the world, the rapid development of science and technology. All this requires people to master as many languages as possible, understand the multi culture, in order to achieve mutual exchanges, mutual learning, mutual promotion and mutual development purposes.

Bilingual Teachers Should Have Special Teaching Strategies and the Comprehensive Ability to be Engaged in Bilingual Teaching. Bilingual teaching is a special teaching activity, which requires bilingual teachers' teaching based on scientific research. Bilingual teaching activities in Colleges and universities, how to make students quickly adapt to this change and actively cooperate with the classroom teaching needs bilingual teachers to adopt some special teaching strategies.

Bilingual teachers should have great affinity and interpersonal skills, and students with different levels of English to establish a good teacher-student relationship. Bilingual teachers should fully understand the students' psychological fear of difficulty, conversion, the initial phase of the transition 
to complete the course work, and using a variety of teaching methods to attract students to use English to answer questions in bold, discuss and complete assignments and exams. Teachers should gradually enter the immersion bilingual teaching method based on the principle of first easy and difficult, so that students have a strong interest in bilingual teaching and actively participate.

Some scholars point out that: "Real 'learning occurs when students use'; students focus on dealing with the relationship between teachers and students." Second language acquisition theory holds that the students' ability of the second language is naturally acquired in a certain language environment. Based on this, bilingual teachers should pay great attention to create a strong bilingual teaching atmosphere. In addition to the use of billboards, corridors and other places posted bilingual phrase accordingly, with a variety of Bilingual School Logo signs, bilingual teachers should also make bilingual charts and posters decorate the classroom with the students, organize all kinds of activities in language communication. Bilingual teachers need to do a lot of preparation work before teaching, not only through a variety of channels to find, collect all aspects of information, selection, integration of teaching content. And make the design of these contents not only easy for students to understand, but also to make students feel challenging, but also the integration of language knowledge and subject knowledge in one, scientific and interesting in one. Bilingual teachers also have the ability to effectively create a cross-cultural language environment, so that students with varying degrees of English can easily and freely communicate, as soon as possible to improve English proficiency.

\section{Ways to Solve Insufficient Bilingual Teaching Staffs in China}

Establish a Perfect and Standard Bilingual Teacher Training System. Bilingual teaching is an inevitable trend of higher education reform and development in china. In view of the shortage of qualified bilingual teachers in our country, we should grasp the training of bilingual teachers as soon as possible and intensify the training of bilingual teachers. Therefore, it is suggested that the relevant departments can establish flexible and perfect bilingual teacher training system as soon as possible.

The feasible way is to strengthen bilingual teacher in-service training and pre-service training. The in-service training of bilingual teachers refers to the special training of excellent teachers selected in Colleges and universities. On-the-job training can be carried out in two stages. On-the-job training can be carried out in two stages. The first stage is to give bilingual teachers intensive training in public English at home. To strengthen and improve the training of bilingual teachers including English listening and speaking, reading and writing, language ability, bilingual education principle and skills, grasp the skills of applying modern teaching method in bilingual teaching and multicultural knowledge etc. This training can not only through the establishment of short-term centralized bilingual education training courses in Normal Universities Bilingual education experts can also be invited to colleges and universities to carry out school-based training of bilingual teachers. The second step is to train the teachers with good training effect to foreign countries to train professional courses, so as to effectively improve the bilingual teachers' English language proficiency and language teaching skills and skills. At the same time, it also enables bilingual teachers to acquire advanced teaching ideas, teaching methods and understanding of multi culture. On-the-job training in two steps can improve training effectiveness and reduce costs.

The so-called pre-service training of bilingual teachers refers to the formal and specialized education and training before the employment. The main channel of bilingual teachers' pre-service training is to set up specialized bilingual teacher training courses or bilingual teacher training courses in normal universities and colleges, and to recruit various levels of students who are interested in bilingual education to receive special training.

At the end of the training, we must pass strict examination, only bilingual level, dual cultural level and bilingual education skills, skills to achieve bilingual teacher standards, before being appointed bilingual teachers. It should be pointed out that, in order to ensure that the gap of bilingual teachers in Colleges and universities has been solved, the training of bilingual teachers should be institutionalized.

Establish Perfect Bilingual Teacher Employment Standards and Evaluation System. The effectiveness of bilingual education is directly related to the cultivation of bilingual talents and the 
development of students, as well as the reputation and survival of bilingual education. Therefore, the government education departments at all levels should develop strict standards and evaluation system for bilingual teachers, and implement bilingual teacher qualification access system. Bilingual teachers should obtain higher education; Secondly, the bilingual teachers' English proficiency, especially oral English pronunciation and the degree of accuracy, and multicultural background knowledge (such as Britain and the United States general knowledge test) of bilingual education and comprehensive ability to rigorously test. Test qualified person can obtain bilingual teacher qualification. At the same time, teachers should be regularly or irregularly tracked and evaluated for the teachers who have obtained bilingual teachers' qualifications, and the teachers with poor teaching effects will cancel their bilingual teachers' qualifications. At the same time, various colleges and universities to carry out bilingual teaching practice activities should be within the existing school qualified bilingual teachers can advance to carry out bilingual teaching. There is a lack of qualified bilingual teachers of the school should suspend the bilingual teaching, do not catch the tide, herd.

Bilingual Teachers Should Have a Series of Rewarding and Stability Policies. Because of the particularity of bilingual teaching, bilingual teaching in teaching than in monolingual much difficulty, preparing volume is many times more than the ordinary monolingual teaching. Based on this situation, all levels of government departments and schools should be excellent or promising bilingual teachers with preferential policies. For example, give appropriate policy support in the title of bilingual teachers' evaluation, bonuses, go out training, truly keep people, keep people, keep people treatment policy feelings, to ensure the high quality of the bilingual teaching vigorously. When necessary, we can also use the talent market adjustment mechanism, so that excellent bilingual teachers in all aspects of good income, thereby attracting outstanding talent to move forward in this field.

Employ Professional Foreign Teachers or Experts and Scholars with Years of Overseas Study Experience as Bilingual Teachers. Foreign professional teachers or experts who have many years of overseas study experience, both in terms of English proficiency or professional level than domestic teachers have advantages. They are familiar with the latest cutting-edge trends in the profession, able to effectively meet the bilingual teaching task of professional courses. But there is a special feature of employing foreign professional teachers, foreign professional teacher's Chinese level is often not satisfactory. It can only adopt the immersion bilingual teaching method, which requires higher English proficiency. There are many years of experience overseas experts and scholars as bilingual teaching is the best choice, but unfortunately this talent gap is too large.

\section{Acknowledgements}

Project: Periodic result of Xi' an social science fund project 16WL01'Research of Basic English Education Development Based on the Background of 'Two-Child Era'"

\section{References}

[1] Sheng Yan. Language Teaching Principle. Chongqing Publishing House, 1989.

[2] Gai Xingzhi. Bilingual Teaching Principle, Yunnan Education Press, 1997.

[3] W.F. Mackay, M. Sigyn. Introduction to Bilingual Education. Translated by Yan Zheng, Liu Xiufeng, Guangming Daily, 1989.

[4] Wu Ping. Review of Bilingual Teaching Research in the Past Five Years, Teaching at Chinese Universities, 2007(1). 
[5] Yan Yezhou. On Bilingual Teaching in Colleges and Universities. Journal of Jiangxi Financial Vocational University, 2007(2).

[6] Hu Jitu, Wang Xiaoxia. Theory and Practice of Bilingual Teaching of "Ideological and Moral Cultivation". Journal of Inner Mongolia Normal University (Education Science Edition), 2007(1).

\section{Author's Profile}

Introduction to the author: Liu Xiuling (1980-), female, from Xi'an, Shaanxi, Master, Lecturer, Research Direction: English teaching methods and English literature

Mailbox:928311869@qq.com

Mailing Address: Xi'an University, No.1, Science \& Technology Road 6, Yanta District, Xi'an, Shaanxi Province Liu Xiuling

Postcode: 710065 Telephones: 13309223716 